\title{
An In Vitro Coculture System for the Detection of Sensitization Following Aerosol Exposure
}

\author{
Aline Chary 1,2, Tommaso Serchi', Elisa Moschini', Jennifer Hennen 2, Sébastien Cambierl, Janine Ezendam³, \\ Brunhilde Blömeke 2 and Arno C. Gutleb ${ }^{1}$ \\ ${ }^{1}$ Department of Environmental Research and Innovation, Luxembourg Institute of Science and Technology, Luxembourg; ${ }^{2}$ Department of Environmental \\ Toxicology, University Trier, Germany; ${ }^{3}$ Centre for Health Protection, National Institute for Public Health and the Environment, The Netherlands
}

\begin{abstract}
The aim of the study was to develop an in vitro model that mimics the alveolar-capillary barrier and that allows assessment of the respiratory sensitizing potential of substances. The 3D in vitro model cultured at the air liquid interface consists of alveolar type II epithelial cells (A549), endothelial cells (EA.hy926), macrophage-like cells (PMA-differentiated THP-1), and dendritic-like cells (non-differentiated THP-1). This alveolar model was exposed apically to nebulized chemical respiratory sensitizers (phthalic anhydride (PA) and trimellitic anhydride (TMA)) or to irritants (methyl salicylate (MeSa) and acrolein (Acr)) at concentrations inducing 25\% cytotoxicity. The exposure to respiratory sensitizers induced dendritic-like cell activation and a specific cytokine release pattern, while exposure to irritants did not. In addition, the cell surface marker OX4OL was found to identify dendritic-like cell activation by high molecular weight allergens. With this in vitro model we can postulate a set of promising markers that allow the discrimination of chemical respiratory sensitizers from irritants.
\end{abstract}

\section{Introduction}

Due to their peculiar toxicity and systemic effects, respiratory sensitizers are receiving increasing attention within toxicity evaluation studies and risk assessment. In certain cases, as stated in Article 57 of the EU REACH Regulation, respiratory sensitizers can be considered substances of very high concern (SVHC) following the principle of equivalent level of concern to carcinogens, mutagens, substances toxic for reproduction, PBT substances (persistent, bio-accumulative, and toxic), and vPvB (very persistent and very bio-accumulative) substances (EC, 2006). The inclusion of a substance on the European Chemicals Agency (ECHA) list for SVHC does not translate to a ban of the substance, but it implies that additional documentation and authorizations are required prior to the placing on the market, use, or import of the substance, which is associated with high expenditure for the company and high potential socioeconomic impact.

Respiratory sensitization to chemical (or low molecular weight; LMW) compounds mostly occurs at the workplace, leading to the development of occupational allergies such as allergic asthma, rhinitis, and conjunctivitis (Kimber et al., 2010). Asthma represents the most prevalent occupational disease of the lungs in developed countries and occupational exposure to dusts, gases, fumes, vapors, and chemicals is responsible for $16 \%$ of asthma in adults (Torén and Blanc, 2009). Around a hundred chemicals were described to act as respiratory sensitizers (Bloemen et al., 2009), among which different chemical classes such as acid anhydrides, diisocyanates, and chloroplatinate salts were identified.

Protein allergens (or high molecular weight; HMW compounds), which are also a potential cause of occupational asthma, are the primary cause for the development of respiratory allergy in the general population. Certain proteins from environmental sources such as pollen, animal dander and house dust mites (HDM) are common causes of asthma. Depending on the geographical location, 50 to $85 \%$ of people with asthma are allergic to certain HDM proteins (Gregory and Lloyd, 2011).

An early identification of compounds with the potential to act as respiratory sensitizers is still difficult. This is due to an incomplete understanding of the systemic mechanisms involved in the development of respiratory sensitization and to the absence of fit-for-purpose, validated, or even widely accepted in vivo models or in vitro assays to identify respiratory sensitizers. Currently,
Received January 24, 2019; Accepted February 19, 2019 Epub February 20, 2019; (C) The Authors, 2019.

ALTEX 36(3), 403-418. doi:10.14573/altex.1901241

Correspondence: Arno C. Gutleb, PhD, Luxembourg Institute of Science and Technology, 5, avenue des Hauts-Fourneaux 4362 Esch/Alzette, Grand-duchy of Luxembourg

(arno.gutleb@list.lu)
This is an Open Access article distributed under the terms of the Creative Commons Attribution 4.0 International license (http://creativecommons.org/licenses/by/4.0/), which permits unrestricted use, distribution and reproduction in any medium, provided the original work is appropriately cited. 
the respiratory sensitizing potential of compounds can only be assessed for regulatory purposes using the rodent LLNA (Local Lymph Node Assay). However, significant differences between the pulmonary and immune systems of rodents and humans make the extrapolation of rodent data to humans difficult. Even though LMW respiratory sensitizers are positive in the LLNA, it is not possible to distinguish respiratory from skin sensitizers using this assay as skin and respiratory sensitization processes share similar mechanisms during the induction phase. Also, the route of exposure in the LLNA is not relevant for the investigation of respiratory sensitizers. In addition to testing a compound in the LLNA, more work is needed to classify it as a respiratory sensitizer, such as evaluation of its cytokine fingerprint and induced IgE serum levels. Thus, it is unclear whether the LLNA is suitable to predict the potency of chemicals to sensitize the respiratory tract (Anderson et al., 2011). In light of the ethical and economic issues surrounding the use of in vivo methods, the development of in vitro alternatives to study respiratory sensitization has been intensified.

It has been suggested that respiratory sensitizers may be identified in an in vitro assay for skin sensitization (Basketter et al., 2017). Even though most chemical respiratory sensitizers tested were positive in assays built for skin sensitization, data are incomplete and several chemical respiratory sensitizers were not identified correctly using skin models. Furthermore, this approach also does not allow the differentiation between skin and respiratory sensitizers.

Dendritic cells (DCs) represent key players in the respiratory sensitization process. In the lower airways, a network of DCs is located directly above and beneath the basement membrane. From this "launch base" DCs project dendrites to sample and take up foreign materials (Lambrecht and Hammad, 2003; van Rijt and Lambrecht, 2005; Holt, 2012; van Helden and Lambrecht, 2013). Upon uptake, DCs can undergo a process of activation and maturation during which they express costimulatory molecules and release cytokines and chemokines (Fig. 1A). For this reason, an in vitro model for identification of respiratory sensitizers should be based on DCs.

Macrophages present in the alveolar interstitium and on the alveolar surface contribute to the first line of defense against inhaled materials and may differentially affect DC function and the induction of adaptive immunity. Interstitial macrophages can prevent DC activation and maturation upon allergen encounter in an IL-10-dependent manner (Sibille and Reynolds, 1990; Bedoret et al., 2009; Toussaint et al., 2013; Lauzon-Joset et al., 2014). Differently, alveolar macrophages, which are mostly involved in removing foreign materials from the alveolar space, can promote an early inflammatory response. Thus, macrophages represent a heterogeneous population that is highly versatile in its responses to foreign materials, which helps to maintain immune homeostasis in the airways (Chung and Adcock, 2014).

Further, events triggered at the alveolar epithelium and the microenvironment created by the other cell types present in the alveolar tissue play an important role in the development of respiratory sensitization. For instance, the alveolar epithelium is a major source of cytokines that direct the immune response and it acts as the first line of defense against airborne pathogens and xenobiotics. With a surface area of up to $100 \mathrm{~m}^{2}$, alveoli represent the largest exposure area of the lung. Besides the alveolar epithelial barrier, the endothelium of the capillary also acts as a structural barrier in the alveolus.

In this work we investigated the in vitro effects of respiratory sensitizers (LMW: phthalic anhydride (PA) and trimellitic anhydride (TMA); HMW: Bet v1 purified protein and house dust mite (HDM) extract) and irritants (methyl salicylate (MeSa) and acrolein (Acr)) at the lung-blood barrier using a novel 3D in vitro coculture model developed by our group on the basis of the lung in vitro model for respiratory irritation developed by Klein et al. (Klein et al., 2013, 2017; Fizeşan et al., 2018) (Fig. 1B). The original model for respiratory irritation combined the alveolar type II epithelial cell line A549 grown on the porous membrane of a Transwell $^{\mathrm{TM}}$ insert and exposed at the air-liquid-interface (ALI), endothelial cells EA.hy926 grown on the basolateral side of the insert, the monocyte cell line THP-1 differentiated into macrophage-like cells, and the human mast cell line HMC-1. This original model was developed to assess the toxic effects of particles at the alveolar barrier. Exposing the system at the ALI mimics the exposure in the alveolus. However, the model described by Klein et al. (2013) is not suitable to identify respiratory sensitizers, since it lacks DCs, which, as described above, are pivotal for the respiratory sensitization process. Therefore modifications, such as addition of DCs to the basolateral compartment, simplifications, such as the removal of mast cells from the model, and optimizations, such as increasing the insert membrane's pore size to allow migration of cells, were necessary in order to generate an in vitro model suitable for the identification of respiratory sensitizers (Fig. 1C).

Different DC-like cell lines have been used to assess the sensitizing potential of chemicals. Among these, undifferentiated THP-1 cells are used in the human cell line activation test (h-CLAT), which represents the first in vitro model adopted by the OECD to replace in vivo testing for skin sensitizers (Ashikaga et al., 2006; OECD, 2018). For this reason, we chose undifferentiated THP-1 cells to represent DCs in our model and measured the modulation of their cell surface marker expression (i.e., CD86 and CD54, also called B7-2 and intracellular adhesion molecule-1 (ICAM-1), respectively) as described for the h-CLAT model, together with other surface markers, soluble mediators (e.g., cytokines and chemokines), and gene expression.

The newly developed lung in vitro model was designed to predict the respiratory sensitization potential of inhaled compounds and to explore additional markers that might increase the accuracy and sensitivity of the testing system. During the characterization of the model, we investigated the effects of the microenvironment generated by the presence of endothelial cells, epithelial cells, and macrophages on the DCs. The alveolar epithelium is in close physical association with DCs and regulates their function by the release of cytokines such as CCL20 or granulocyte-macrophage colony-stimulating factor (GM-CSF), which promote Th2 responses, thus influencing DC maturation and the outcome of the immune response (van Rijt and Lambrecht, 2005; Hammad and Lambrecht, 2011; Schuijs et al., 2013; Lambrecht and Hammad, 2015). 
A

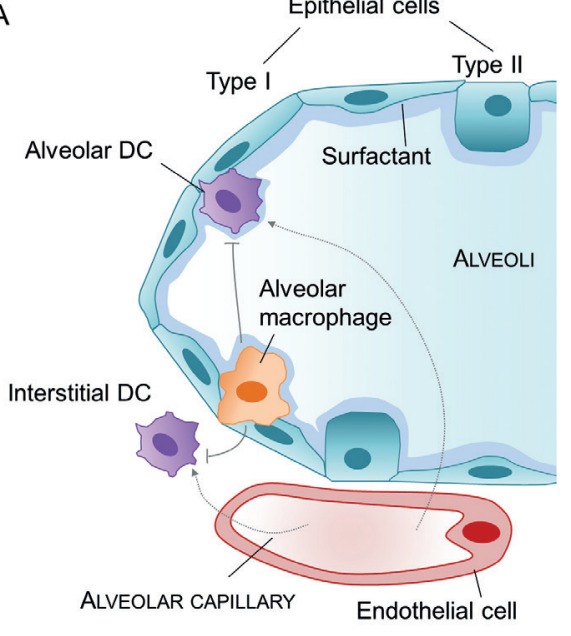

B

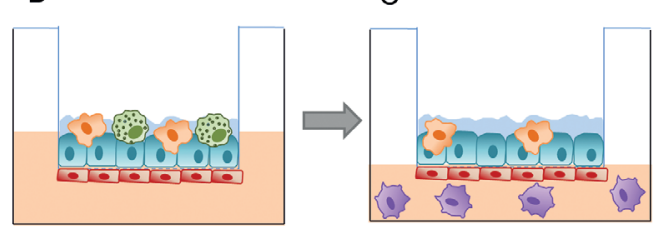

: Macrophages (THP-1 differentiated with PMA)

: Alveolar type II epithelial cells (A549)

Dendritic-like cells (THP-1)

: Endothelial cells (EA.hy 926)

: Mast cells (HMC-1)

: Surfactant

: Medium

Fig. 1: The alveolar barrier and the in vitro system

(A) Schematic representation of the in vivo alveoli. The alveolus represent an extensive surface area. The close contact of alveolar epithelial cells and endothelial cells from the capillary allows gaseous exchange. Surfactant, produced by type II epithelial cells, lowers the surface tension and participates in alveolar host defense mechanisms by interacting with immune cells such as alveolar macrophages to bind and remove foreign material. Dendritic cells (DCs) are located above and beneath the basement membrane. Alveolar macrophages play an active role in the immune response and modulate DC function. (Adapted and modified from Lambrecht and Hammad, 2003; Whitsett and Alenghat, 2015), (B) Coculture system previously developed by Klein et al. (2013) to study the inflammatory effect of NPs at the alveolar barrier. Cells were seeded on a porous membrane of a Transwell ${ }^{\mathrm{TM}}$ insert, cultured at the air liquid interface (ALI) and exposed to aerosol. (C) Modification of the coculture system to allow assessment of the respiratory sensitizing potential of chemical or protein compounds (adapted and modified from Chary et al., 2017; WO2018/122219 A1).

Some promising models have been developed in the last years to study the respiratory sensitization potential of chemicals (Huang et al., 2013; Dik et al., 2015; Forreryd et al., 2015; Hermanns et al., 2015; Mizoguchi et al., 2017); however, they target only one of the key events leading to the adverse outcome of respiratory sensitization. It is widely assumed that, like for skin sensitization, a single in vitro assay modeling only one key event of respiratory sensitization would not be sufficient to determine the respiratory sensitizing potential of compounds. For skin sensitization, an integrated test strategy (ITS) combining validated models that represent at least two key events of the adverse outcome pathway (AOP) of skin sensitization is required to accurately determine the sensitizing potential of chemicals (Clouet et al., 2017; Otsubo et al., 2017; Strickland et al., 2017; Ohtake et al., 2018). An AOP for respiratory sensitization based on key steps of the AOP for skin sensitization but with specific differences was recently proposed (Kimber et al., 2014; Sullivan et al., 2017). This AOP includes (1) protein-binding reactions as the molecular initiating event, followed by key events corresponding to (2) the epithelial response with the release of danger signals and cytokines, (3) DC activation which preferentially promotes a pro-Th2 environment, and (4) Th2 cell proliferation (Sullivan et al., 2017). By measuring cytokines released at the alveolar barrier and by evaluating the activation of DCs, our model addresses key events 2 and 3 of the AOP. Several parameters could be added to complete the set of markers required to address the other key events involved in respiratory sensitization.

\section{Material and methods}

Chemicals and protein allergens

Phthalic anhydride (PA) (Sigma-Aldrich), trimellitic anhydride (TMA) (Sigma-Aldrich) and methyl salicylate (MeSa) (SigmaAldrich) were dissolved in DMSO (Sigma-Aldrich); acrolein (Acr) (Sigma-Aldrich), lipopolysaccharide (LPS) (from E. coli, Sigma-Aldrich), purified natural birch pollen (Bet v1, Indoor biotechnologies, Cardiff, UK), and house dust mite extract (HDM, Citeq biologics, Groningen, The Netherlands, endotoxin content $1.1 \times 10^{6} \mathrm{EU} / \mathrm{g}$ ) were dissolved in sterile water.

\section{Cell lines}

The human cell lines A549 (Lieber et al., 1976), THP-1 (Tsuchiya et al., 1980), and EA.hy926 (Butterfield et al., 1988) were obtained from ATCC. The cells were cultured using respective culture media (Tab. 1). Adherent cell lines were trypsinized twice 
Tab. 1: List of media used for monoculture and coculture

DMEM, Dulbecco's Modified Eagle's Medium; RPMI-1640, Roswell Park Memorial Institute 1640; IMDM, Iscove's Modified Dulbecco's Medium (Gibco, Erembodegem, Aalst, Belgium); FBS, Fetal Bovine Serum Superior (Millipore, Deisenhofen, Germany); penicillin-streptomycin (Gibco, Erembodegem, Aalst, Belgium), HEPES (Sigma-Aldrich, Deisenhofen, Germany), and $\beta$-mercaptoethanol (Bio-rad, Temse, Belgium)

\begin{tabular}{|l|l|l|l|}
\hline Cell line & Medium & Serum & Supplement \\
\hline A549 & DMEM & $10 \%(\mathrm{v} / \mathrm{v})$ FBS & $10 \%$ penicillin-streptomycin \\
\hline THP-1 & RPMI-1640 & $10 \%(\mathrm{v} / \mathrm{v})$ FBS & $\begin{array}{l}25 \text { mM HEPES; } 50 \mu \text { M } \beta \text {-mercaptoethanol; } \\
10 \% \text { penicillin-streptomycin }\end{array}$ \\
\hline EA.hy926 & DMEM & $10 \%(\mathrm{v} / \mathrm{v})$ FBS & 25 mM HEPES; $10 \%$ penicillin-streptomycin \\
\hline Coculture $10 \%$ of FBS & $\begin{array}{l}75 \% \text { DMEM } \\
15 \% \text { RPMI-1640 } \\
10 \% \text { IMDM }\end{array}$ & $10 \%(\mathrm{v} / \mathrm{v})$ FBS & 25 mM HEPES; $10 \%$ penicillin-streptomycin \\
\hline Coculture $1 \%$ of FBS & $\begin{array}{l}75 \% \text { DMEM } \\
15 \% \text { RPMI-1640 } \\
10 \% \text { IMDM }\end{array}$ & $1 \%(\mathrm{v} / \mathrm{v})$ FBS & 25 mM HEPES; $10 \%$ penicillin-streptomycin \\
\end{tabular}

a week and medium was changed every other day. Cells were maintained in a humidified atmosphere with $5 \% \mathrm{CO}_{2}$ at $37^{\circ} \mathrm{C}$ and tested regularly for mycoplasma contamination. The identity of each cell line (A549, THP-1, and Ea.hy926) used in the present work was confirmed via the human STR profiling cell authentication service provided by American Type Culture Collection (ATCC, Manassas, VA, USA).

\section{THP-1 cell migration assay}

The ability of THP-1 cells to migrate between compartments through the membrane of a Transwell ${ }^{\mathrm{TM}}$ insert was tested using 1, 3,5 , and $8 \mu \mathrm{m}$ pore size PET membrane Transwell ${ }^{\mathrm{TM}}$ inserts (Millipore). $1.5 \times 10^{6}$ cells $/ \mathrm{ml}$ were seeded on the apical side of each insert. 0,50 , and $100 \mathrm{ng} / \mathrm{ml}$ of monocyte chemoattractant protein-1 (MCP-1) (Sigma) was added to THP-1 medium on the basolateral side of the inserts. After $2 \mathrm{~h}$, cells that had migrated through the membrane were counted microscopically. Trypan blue was used for determination of dead cells (dilution 1:2 v/v in trypan blue). The percentage of migrated cells was calculated as number of cells in the basolateral compartment/total number of cells x 100 .

\section{Exposure of monocultures}

THP-1 cells $\left(1 \times 10^{6}\right.$ cells $\left./ \mathrm{ml}\right)$ in THP-1 medium (Tab. 1$)$ were exposed to different concentrations of chemicals and to their vehi- cle controls in 24-well-plates. Concentration of vehicle control did not exceed $0.2 \%$. Viability of THP-1 cells was assessed after $24 \mathrm{~h}$ exposure to chemicals using $1 \mu \mathrm{M}$ Sytox Blue (Thermofischer) by cytofluorimetric analysis on a SLR Fortessa system (BD Biosciences, Heidelberg, Germany) and analyzed using the FlowJo software (V10) (Ashland, Oregon, USA).

\section{Coculture workflow}

On day 0 , THP-1 cell differentiation into macrophage-like cells was performed by seeding $4 \times 10^{5}$ cells $/ \mathrm{ml}$ in THP- 1 medium, adding $20 \mathrm{ng} / \mathrm{ml}$ phorbol-12-myristate-13-acetate (PMA; Sigma, Deisenhofen, Germany) and incubating cells over night at $37^{\circ} \mathrm{C}$ and $5 \% \mathrm{CO}_{2}$. On day 1, PMA-containing medium was replaced by fresh THP-1 complete medium and cells were incubated for a further 5 days.

On day 2, EA.hy926 and A549 cells were seeded on Millipore cell culture inserts (surface area of $4.5 \mathrm{~cm}^{2} ; 5 \mu \mathrm{m}$ pore size; high pore density PET membranes for 6-well plates; Millipore, Molsheim, France). EA.hy926 cells were seeded on inverted Transwell ${ }^{\mathrm{TM}}$ inserts $\left(2.4 \times 10^{4}\right.$ cells $\left./ \mathrm{cm}^{2}\right)$. Upon attachment on the basolateral side of the Transwell ${ }^{\mathrm{TM}}$ insert after $4 \mathrm{~h}$, the plate with the transwell inserts was turned back and the A549 cells were seeded on the apical side $\left(6 \times 10^{4}\right.$ cells $\left./ \mathrm{cm}^{2}\right)$. EA.hy926 and A549 cells were grown for 3 days at $37^{\circ} \mathrm{C}$ and $5 \% \mathrm{CO}_{2}$ in a humidified incu-

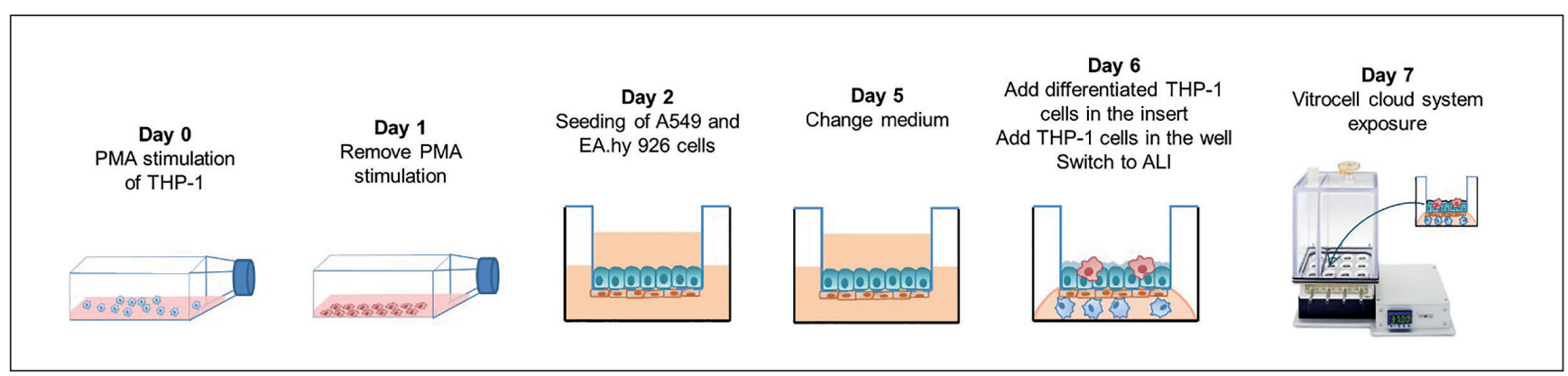

Fig. 2: Workflow for the seeding and exposure of the in vitro coculture model 
bator. On day 5 , medium was replaced by complete coculture medium containing 10\% FBS. On day 6 , differentiated THP-1 (2.4 x $10^{4}$ cells $/ \mathrm{cm}^{2}$ ) cells were added into the inserts on top of the confluent layer of A549. Upon attachment, typically after $4 \mathrm{~h}$, medium was removed from the upper compartment and the coculture was cultivated overnight at the ALI until exposure (Fig. 2).

\section{Aerosol exposure}

The Vitrocell ${ }^{\circledR}$ Cloud-6 system (Vitrocell ${ }^{\circledR}$, Waldkirch, Germany) was used for the exposure of the in vitro coculture model to test compounds and vehicle controls. Stock solutions were diluted in $50 \%(\mathrm{v} / \mathrm{v})$ sterile water in PBS (1X). The system's vibrating membrane generates aerosol from liquids and suspensions in a closed chamber. The cloud of aerosol settles on the cultivation module, which is heated to $37^{\circ} \mathrm{C}$, usually within a period of $15 \mathrm{~min}$, allowing the simultaneous exposure of up to six cell culture inserts. The nebulized cloud allows a dose-controlled and spatially uniform aerosol deposition on the top of the inserts.

\section{Assessment of cell viability}

$24 \mathrm{~h}$ after exposure to the test compounds and controls, the viability in the cocultures was assessed using $400 \mu \mathrm{M}$ Alamar Blue diluted in culture medium. After $1 \mathrm{~h}$ incubation at $37^{\circ} \mathrm{C}$ in the dark, medium was collected from the apical and basolateral compartments and the fluorescence measured at $530 \mathrm{~nm}$ excitation and $590 \mathrm{~nm}$ emission using a fluorescence microplate reader (Spark 20M, Tecan, Mechelen, Belgium).

\section{Flow cytometry measurements}

After $24 \mathrm{~h}$ exposure, THP-1 cells were collected from the basolateral compartment of the wells and stained with fluorescence-labelled monoclonal antibodies and isotype-matched controls (mouse IgG1). PE anti-CD86 (clone 2331 [FUN-1]), APC anti-CD54 (clone HA58), and PE-anti OX40L (clone ik-1) were purchased from BD Pharmingen, (Heidelberg, Germany) and AF647 anti-CD127 (IL7R $\alpha$ ) (clone A019D5) and APC anti-TSLPR (clone 1B4) were purchased from BioLegend (London, UK).

Surface marker expression was measured using SLR Fortessa system and analyzed with FlowJo software V10. Sytox Blue-positive cells (dead cells) were excluded from the analysis. Relative geometric mean fluorescence intensities (rMFI) were expressed in $\%$ and calculated as follows:

\section{MFI sample - MFI isotype sample MFI vehicle - MFI isotype vehicle}

\section{Cytokine release}

$24 \mathrm{~h}$ after exposure, aliquots from the medium in the basolateral compartment were collected and GM-CSF, CCL20, IL-6, IL-10, IL-7, MCP-1, RANTES, sCD40L, IL-33, IL-25, and IL-1 $\alpha$ were quantified. Quantification was performed on a Luminex $200^{\mathrm{TM}}$ (Luminex Corporation, Oosterhout, The Netherlands) using the MILLIPLEX MAP Human Cytokine/Chemokine Magnetic Bead Panel - Immunology Multiplex Assay and the MILLIPLEX MAP
Human TH17 Magnetic Bead Panel - Immunology Multiplex Assay (Millipore) following the manufacturer's instruction.

\section{Gene expression}

$24 \mathrm{~h}$ after exposure, total RNA was isolated from THP-1 cells, which are floating cells isolated from the basolateral compartment, using the RNeasy Mini Kit (Qiagen, Leusden, The Netherlands) according to the manufacturer's protocol. A Nanodrop ND1000 spectrophotometer (Thermo Scientific, Villebon-sur-Yvette, France) was used to measure the purity and the concentration of extracted RNA. The Agilent 2100 Bioanalyzer electrophoretic system (Agilent Technologies, Diegem, Belgium) was used to verify the integrity of extracted RNA. All samples displayed high purity and RNA integrity values (RINs) above 8 , making them suitable for qRT-PCR. cDNAs were prepared from $1 \mu \mathrm{g}$ RNA using the following reagents: Protoscript II reverse transcriptase and murine RNase inhibitor (New England Biolabs, Ipswich, MA, USA), dNTPs (Promega), and random primers (Invitrogen, Carlsbad, NM, USA) following the manufacturer's instructions.

qRT-PCR was then performed on a ViiA 7 Real-Time PCR System (Thermo Scientific, Villebon-sur-Yvette, France) using the Takyon low ROX SYBR MasterMix dTTP Blue Kit (Eurogentec, Liège, Belgium) on $10 \mu \mathrm{l}$ qRT-PCR mix with the following concentrations: 1x MasterMix, $100 \mathrm{nM}$ of each forward and reverse primer, and $0.4 \mathrm{ng} / \mu \mathrm{l}$ of cDNA. The thermal cycling conditions were as follows: denaturation for $5 \mathrm{~min}$ at $95^{\circ} \mathrm{C}$, followed by 45 cycles of denaturation for $15 \mathrm{sec}$ at $95^{\circ} \mathrm{C}$ and annealing and extension for $1 \mathrm{~min}$ at $60^{\circ} \mathrm{C}$. A final dissociation step (melting curve) was used to determine primer specificity. No-template and genomic DNA controls were added to each plate to exclude possible contamination from the used reagents and the presence of genomic DNA. All PCR reactions were carried out in triplicates. Gene expression analysis was calculated based on the $\Delta \Delta \mathrm{CT}$ method using the Biogazelle qbase PLUS software 2.5 (Gent, Belgium). Four reference genes (B2M, HPRT1, YWHAZ, SDHA) were selected in agreement with our previous study (Klein et al., 2017) and the most stable candidates between experimental samples were determined using GeNorm in the Biogazelle qBase PLUS software and used for the analysis of the qRTPCR results. The list of primers for the reference genes and genes of interest is summarized in Table 2 .

\section{Statistical analysis}

All results are presented as means \pm S.E.M. Data were analyzed with an unpaired Student's t-test, or by one-way ANOVA using GraphPad Prism software (GraphPad Software Inc., San Diego, CA, USA). The macro Regtox on Excel software (Microsoft, USA) was used to determine the CV75. Differences between groups were considered statistically significant when $p<0.05$. Table $\mathrm{S} 1^{1}$ summarizes comprehensive information such as the $\mathrm{n}$ values, statistical tests, $p$ values, $F$ values, and degrees of freedom used to do the statistical analyses.

Linear discriminant analysis was done using PAST3 software.

1 doi:10.14573/altex.1901241s 
Tab. 2: Primer sequences used for qRT-PCR experiments on RNA isolated from THP-1 cells on the basolateral side of the coculture

\begin{tabular}{|c|c|c|}
\hline Gene & Forward primer $\left(5^{\prime} \rightarrow 3^{\prime}\right)$ & Reverse primer $\left(5^{\prime} \rightarrow 3^{\prime}\right)$ \\
\hline IL1RL1 & AGAAATCGTGTGTTTGCCTCA & CGCATATCCAGTCCTATTGAATG \\
\hline$B C L 2 L 1$ & GAGCTGGTGGTTGACTTTCTC & TCCATCTCCGATTCAGTCCCT \\
\hline$C D 80$ & GGCCCGAGTACAAGAACCG & TCGTATGTGCCCTCGTCAGAT \\
\hline$C D 86$ & CTGCTCATCTATACACGGTTACC & GCTGATGGAAACGTCGTACA \\
\hline$C D 8 a$ & GCCTTACCAGTGACCGCCTT & AGGTTCCAGGTCCGATCCAG \\
\hline IL7R & TGTCGTCTATCGGGAAGGAG & CGGTAAGCTACATCGTGCATTA \\
\hline GCSFR & TGGAGCTGAGAACTACCGAA & CCTGAGGGTCTCCAAGAAA \\
\hline MyD88 & GGCTGCTCTCAACATGCGA & CTGTGTCCGCACGTTCAAGA \\
\hline MAP2K2 & CCAAGGTCGGCGAACTCAAA & TCTCAAGGTGGATCAGCTTCC \\
\hline MAP2K1 & CAATGGCGGTGTGGTGTTC & GATTGCGGGTTTGATCTCCAG \\
\hline PSME3 & АTCTCCCAGTCССTGACCC & TCATCCAACCTTCGCTTCTTAT \\
\hline PSMB5 & AGGAACGCATCTCTGTAGCAG & ССТСТСТTАТСССАGССАСА \\
\hline CIITA & TTATGCCAATATCGCGGAACTG & CATCTGGTCCTATGTGCTTGAAA \\
\hline HLADRA & ATACTCCGATCACCAATGTACCT & GACTGTCTCTGACACTCCTGT \\
\hline HLADMA & GACAAAGAGTTCTGCGAGTGGA & ACACTTCAGCGATAGGAAACCC \\
\hline LY96 & GCCGAGGATCTGATGACGA & GATGACAAACTCCAAGCAAAAG \\
\hline$B 2 M^{1}$ & TGCTGTCTCCATGTTTGATGTATCT & TCTCTGCTCCССАССТСTAAGT \\
\hline HPRT-1 1 & TGACACTGGCAAAACAATGCA & GGTCCTTTTCACCAGCAAGCT \\
\hline$Y W H A Z^{1}$ & ACTTTTGGTACATTGTGGCTTCAA & CCGCCAGGACAAACCAGTAT \\
\hline$S D H A^{1}$ & TGGGAACAAGAGGGCATCTG & CCACCACTGCATCAAATTCATG \\
\hline
\end{tabular}

1 described in Klein et al. (2017)

\section{Results}

\subsection{Development of a functional in vitro system of the alveolar barrier to assess respiratory sensitization}

To model the alveolar anatomy and functionality, DCs seeded on the basolateral side of the Transwell ${ }^{\mathrm{TM}}$ insert must be able to migrate to the apical side in order to capture antigens and initiate the sensitization process. A chemotaxis assay was performed to determine a membrane pore size for the Transwell ${ }^{\mathrm{TM}}$ inserts that allows migration of THP-1 DC-like cells (Fig. S1A ${ }^{1}$ ). The percentage of THP-1 cells that had migrated through $1,3,5$, and $8 \mu \mathrm{m}$ pore size membrane inserts $2 \mathrm{~h}$ after exposure to 0,50 , and $100 \mathrm{ng} / \mathrm{ml}$ of MCP-1 was evaluated. No migration to very low migration was observed using the 1 and $3 \mu \mathrm{m}$ pore size membranes for all tested concentrations of MCP-1 (Fig. S1B ${ }^{1}$ ). The $8 \mu \mathrm{m}$ pore size inserts allowed the migration of THP-1 cells even in the absence of chemoattractant and the concentration response curve in response to MCP-1 was rather flat. The basal migration rate through the $5 \mu \mathrm{m}$ pore size inserts in the absence of chemoattractant was about $2 \%$ and increased concentration-dependently to $12 \%$ at the highest concentration of MCP-1. No influence of the $5 \mu \mathrm{m}$ pore membrane insert on cell viability (Fig. $\mathrm{S}^{1} \mathrm{C}^{1}$ ) or on lung surfactant production (Fig. S1E ${ }^{1}$ ) was observed in comparison to the original $1 \mu \mathrm{m}$ pore membrane insert (Klein et al.,
2013). Therefore, the $5 \mu \mathrm{m}$ pore size membrane insert was used to build the in vitro co-culture system.

Compared to the original model (Klein et al., 2013, 2017), endothelial cell density was reduced to $2.4 \times 10^{4}$ cells $/ \mathrm{cm}^{2}$ to avoid the presence of detached, dead endothelial cells and cellular debris in the basal compartment.

The volume of cell culture medium in the basal compartment was reduced from 2 to $1 \mathrm{ml}$ to avoid leakage of medium to the apical compartment owing to the larger membrane pore size. Leakage would submerge epithelial cells, which would then no longer be at the ALI, and influence the surfactant. The change in volume did not affect the viability of the cells (Fig. S1D ${ }^{1}$ ).

To allow stable differentiation of THP-1 cells into macrophage-like cells, incubation of THP-1 cells with PMA was followed by a 5-day resting period. Resting allows macrophages to express surface markers associated with macrophage differentiation (such as the upregulation of CD11b, CD44 and CD49e, and the downregulation of CD14 and TLR2) in a pattern similar to in vivo macrophages (Daigneault et al., 2010). The macrophage resting period also allows the reduction of the basal level of inflammation of the system (Marescotti et al., 2019).

To best mimic the in vivo situation, the coculture system was further optimized for exposure at the ALI (Lacroix et al., 2018). We used the Vitrocell ${ }^{\circledR}$ cloud system with a modified basement 
A

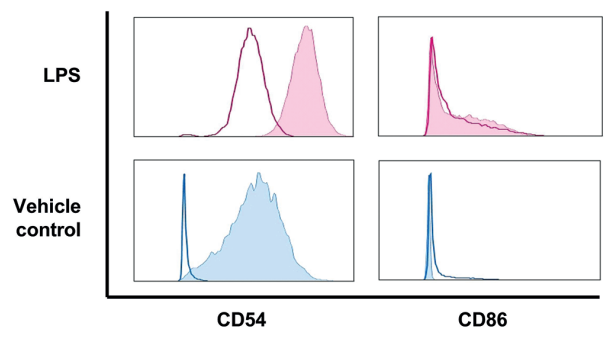

B

C

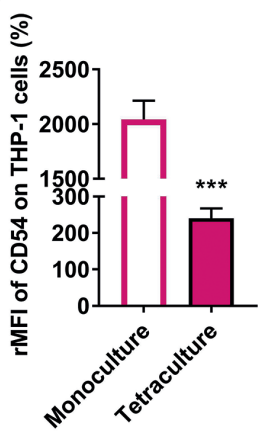

号
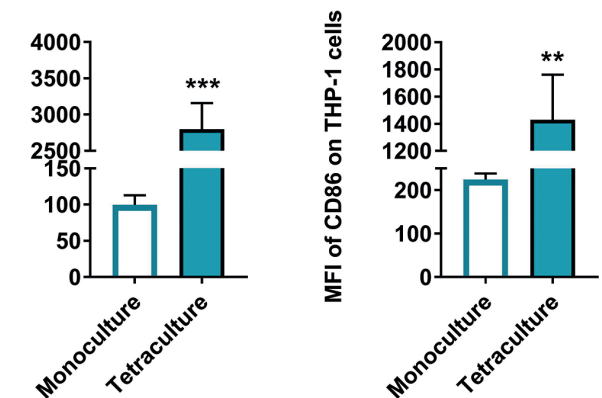
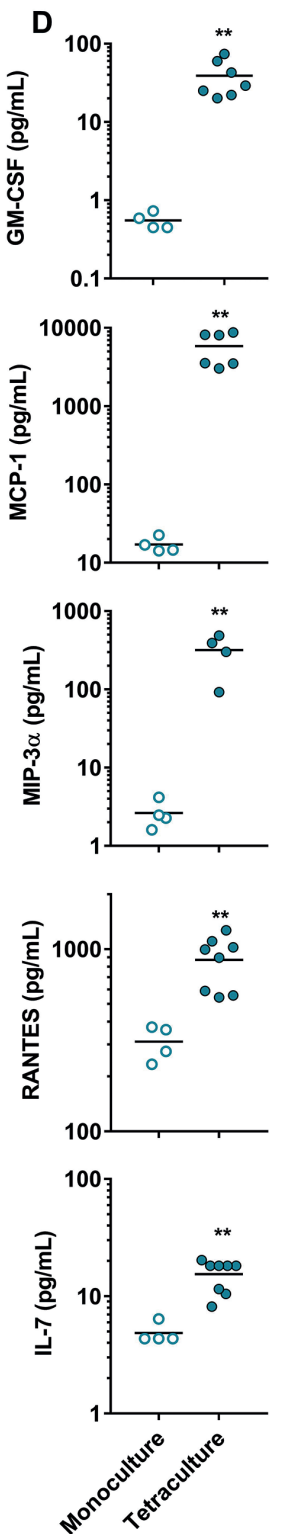

Fig. 3: Basal and LPS-induced expression of CD54 and CD86 on THP-1 cells and basal cytokine release in the monoculture versus coculture (A) Representative flow cytometric measurement of basal and LPSstimulated expression of CD54 and CD86 costimulatory molecules on THP-1 cells in submerged conditions in monoculture or upon exposure at the air-liquid interface in the coculture. (B) Basal expression of CD54 and CD86 costimulatory molecules on THP-1 cells in monoculture versus coculture in $24 \mathrm{~h}$ (mean \pm SEM; $\mathrm{t}$-test, $\mathrm{n}=4$ (monoculture), $\mathrm{n}=3$ (coculture)). (C) LPSinduced expression of CD54 and CD86 24 $\mathrm{h}$ after exposure (mean $\pm \mathrm{SEM}$; t-test, $\mathrm{n}=4$ (monoculture), $\mathrm{n}=3$ (coculture). (D) Basal cytokine (GM-CSF, MCP-1, MIP-3a/CCL20, RANTES, and IL-7) levels released into the medium in monoculture versus coculture (scatter plot and mean) (GM-CSF, $\mathrm{n}=4$ (monoculture), $\mathrm{n}=7$ (coculture); MCP-1, $\mathrm{n}=4$ (monoculture), $\mathrm{n}=6$ (coculture); MIP3a, $\mathrm{n}=4$ (monoculture), $\mathrm{n}=4$ (coculture); RANTES, $n=4$ (monoculture), $n=8$ (coculture); IL-7, $\mathrm{n}=4$ (monoculture) and $\mathrm{n}=8$ (coculture)). module into which the inserts are placed during aerosol exposure to allow the deposition of the aerosol only on the apical side of the insert (Lenz et al., 2009). To ensure that the exposure occurs exclusively onto the apical side of the inserts, a custom-made sealing device (Vitrocell ${ }^{\circledR}$, Waldkirch, Germany) was used to seal the empty space between the inserts and the exposure module (Fig. S2A-D ${ }^{1}$ ). Exposure to water or DMSO vehicle control aerosols did not induce any statistically significant effects on cell viability after $24 \mathrm{~h}$ and $48 \mathrm{~h}$ as compared to unexposed inserts kept in the incubator (Fig. S2E $\mathrm{E}^{1}$ ).

\subsection{Influence of the microenvironment on THP-1 cells}

To characterize the impact of the multicellular environment on THP-1 cells, we compared cell surface marker expression of
CD54 and CD86 on THP-1 cells after exposure to chemicals in monoculture and in coculture.

The basal levels of CD54 and CD86 on THP-1 cells were determined in monoculture and coculture in the absence of external stimuli. Basal levels of both CD54 (28-fold) and CD86 (6-fold) were higher in the alveolar coculture model (Fig. 3A-B) than in the monoculture.

LPS-induced cell surface marker expression was compared in THP-1 cells in monoculture and in coculture after $24 \mathrm{~h}$ exposure. Despite not being a respiratory sensitizer itself, LPS is known to exacerbate the allergic response and respiratory inflammation (Liu, 2002; Kumari et al., 2015). LPS exposure did not affect cellular viability in monoculture or coculture. Exposure of THP-1 cells in both culture conditions to LPS induced a slightly 
increased expression of CD86 (165\% in monoculture and 139\% in coculture in comparison to vehicle control, not statistically significant) and greatly increased expression of CD54 (2044\% in monoculture and $240 \%$ in coculture in comparison to vehicle control) (Fig. 3A-C).

In order to better understand the effect of the microenvironment on THP-1 cells, basal cytokine release was measured in supernatants after $24 \mathrm{~h}$ in both culture conditions. Significantly higher basal levels of the measured mediators were found in coculture compared to monoculture: RANTES (3 times), GM-CSF (70 times), CCL20 (122 times), and MCP-1 (344 times) (Fig. $3 \mathrm{D})$. In the coculture, $53 \mathrm{pg} / \mathrm{ml}$ IL-6, which is involved in the regulation of CD54, was measured in the medium, while its concentration in monoculture was below the detection limit $(0.6 \mathrm{pg} / \mathrm{ml})$ (Fig. S3B ${ }^{1}$ ). The pro-Th2 cytokine IL-1 $\alpha$ was below the limit of detection $(9.4 \mathrm{pg} / \mathrm{ml})$ for both coculture and monoculture. However, it was possible to extrapolate the value only for the coculture to $2.8 \mathrm{pg} / \mathrm{ml}$. The pro-Th2 cytokine IL-7 (3 times higher in coculture) (Fig. 3D) and the anti-inflammatory cytokine IL-10 $(15 \mathrm{pg} / \mathrm{ml}$ in coculture but below the detection limit of $1.1 \mathrm{pg} / \mathrm{ml}$ in monoculture) were also present in higher concentrations in the coculture than in the monoculture.
LPS-induced cytokine release and gene expression in THP-1 cells were also measured in the coculture. LPS stimulation led to an increased release of IL-6, CCL20, RANTES, IL- $1 \alpha$, GM-CSF, and IL-10 in the coculture (Fig. S3A ${ }^{1}$ ). IL-10 production is known to affect DC function by downregulating surface expression of class II MHC molecules (Akdis et al., 2011) that could be linked to the down regulation of CIITA and HLA-DMA gene expression in our model (Fig. S3B ${ }^{1}$ ). G-CSFR and MyD88 gene expression were also downregulated in response to LPS stimulation while MAP2K1 and CD80 expression were upregulated (Fig. S3B ${ }^{1}$ ).

\subsection{Assessing the respiratory sensitization potential of chemicals in the coculture versus monoculture model}

We first compared the response of established sensitization markers on THP-1 cells (i.e., CD54 and CD86) when exposed directly in submerged monoculture conditions to respiratory sensitizers and respiratory irritants (following the h-CLAT protocol) or within the coculture system at the ALI. Experiments were designed to evaluate the possible benefit of the coculture system for the assessment of respiratory sensitization, keeping in mind that in vitro models should be "as complex as necessary and as simple as possible" (Pridgeon et al., 2018).
A

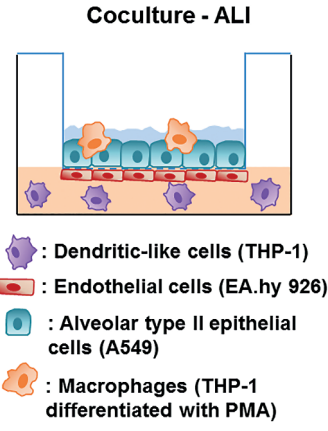

B

Monoculture - submerged

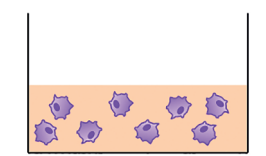

: Dendritic-like cells (THP-1)

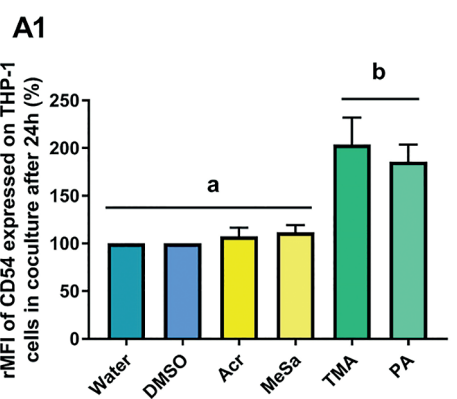

B1

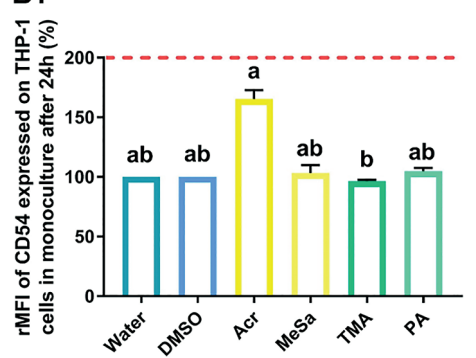

A2

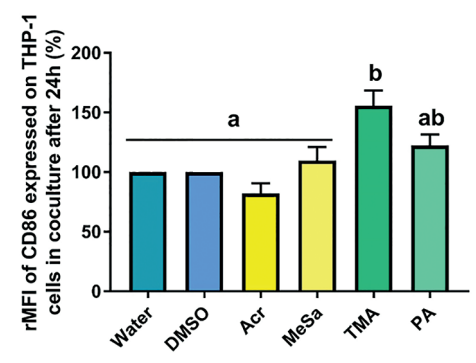

B2

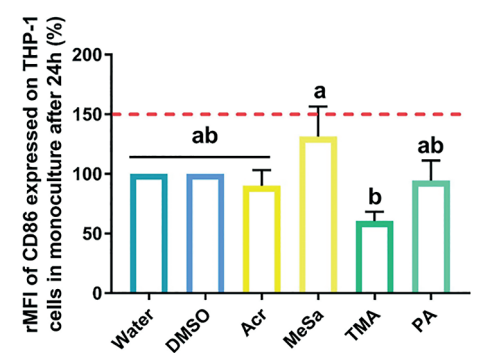

Fig. 4: Differentiation of respiratory sensitizers and irritants based on CD54 expression but not CD86 expression on THP-1 cells in coculture

Exposure of THP-1 cells to chemical respiratory sensitizers and irritants through exposure at the air liquid interface in the coculture (A) versus under submerged conditions in monoculture (B). Relative mean of fluorescence intensity (rMFI, \%) of CD54 measured $24 \mathrm{~h}$ after exposure of THP-1 cells to chemical sensitizers or irritants in coculture $(A 1, n=3)$ and in monoculture $(B 1, n=4$ (water, DMSO, Acr, MeSa), $\mathrm{n}=3$ (TMA, PA)) and of CD86 in coculture $(A 2, n=3)$ and in monoculture (B2, $n=4$ (water, DMSO, Acr, MeSa), n=3 (TMA, PA)). Red dotted lines represent the threshold levels used in the human-cell line activation ( $h-C L A T)$ test to differentiate between positive and negative compounds (mean \pm SEM, ANOVA + Tukey post hoc test except B1, Kruskal-Wallis test + Dunn's multiple comparisons test) (Groups that share the same letters are not significantly different $(p>0.05))$. 
It has been found in the h-CLAT that many skin sensitizing chemicals require a certain level of cytotoxicity to induce sufficient activation of THP-1 cells. Both for monoculture and for coculture, a working concentration of chemicals (respiratory irritants and sensitizers) leading to $75 \%$ cell viability (CV75) was established as prescribed by the h-CLAT protocol, which led to the best results for cell surface marker expression (Sakaguchi et al., 2009). Non-toxic and poorly soluble compounds were used at their limit of solubility. The same cell density $\left(1.0 \times 10^{6}\right.$ cells/ $\mathrm{ml}$ ) of THP-1 cells was used in both the monoculture and the coculture systems. However, it must be considered that the coculture consists of three additional cell types instead of only one in the monoculture. Thus, the relative concentration of the test compounds and the resulting calculated dose ( $\mu \mathrm{g}$ of compound per $10^{6}$ cells in coculture) is lower for the coculture than the monoculture. Contrary to the monoculture, where cytotoxicity was assessed using Sytox blue (a nucleic acid stain) for its good reproducibility and rapid measurement, the Alamar Blue assay was used to evaluate viability in the cocultures, since it allows the assessment of overall cell viability in the whole Transwell ${ }^{\mathrm{TM}}$ module. Dose response curves of viability were obtained after exposure of cocultures to Acr, PA, and TMA (Fig. S4A ${ }^{1}$ ). No cytotoxicity was observed after exposing cells to MeSa at the concentration corresponding to the maximum solubility of the compound $\left(56 \mu \mathrm{g} / \mathrm{cm}^{2}\right)$. For the monoculture of THP-1 cells, it was possible to obtain a dose response curve only for Acr, which was used for the following experiments at the concentration corresponding to the CV75. For the other chemicals the concentrations corresponding to maximum solubility were used, since it was not possible to reach CV75 (Fig. S4B ${ }^{1}$ ). The CV75 values determined for monoculture and coculture are reported in Figure $\mathrm{S} 4 \mathrm{C}^{1}$.

In THP-1 monoculture (Fig. 4B), exposure to the respiratory sensitizers PA and TMA or the irritant MeSa did not influence the expression of CD54. Acr exposure led to a modest CD54 upregulation to $165 \%$, which was below the threshold of $200 \%$ set for the h-CLAT at which a compound would be considered a sensitizer (Fig. 4B1). Similar results were obtained for CD86 expression in the THP-1 cell monocultures (Fig. 4B2).

Exposure of the coculture to the sensitizers PA and TMA led to a significant up-regulation of the expression of CD54 on the surface of THP- 1 cells to $186 \%$ and $204 \%$, respectively, as compared to vehicle controls, while no increase was observed for the respiratory irritants $\mathrm{MeSa}$ and Acr (Fig. 4A1). This allows a clear discrimination between respiratory sensitizers and irritants.

With regard to the cell surface marker CD86, TMA showed an upregulation to $156 \%$, whereas PA exposure only led to a $122 \%$ upregulation. Exposure to the respiratory irritant MeSa induced a slight increase of CD86 expression of $110 \%$ as compared to the vehicle control, while the respiratory irritant Acr induced a downregulation to $82 \%$ as compared to the vehicle control (Fig. 4A2).

\subsection{Additional markers to predict chemical respiratory sensitization potential}

\subsubsection{Cell surface markers}

OX40L, TSLPr, and IL7-R $\alpha$, which are involved in the respiratory sensitization process, were evaluated for their potential use in the in vitro prediction of the respiratory sensitization potential of airborne chemical substances.

Naïve T cell differentiation into Th2 cells strongly depends on co-stimulatory molecules expressed by DCs. One of the most critical co-stimulatory molecules is the receptor OX40, expressed by T-cells, and its ligand OX40L. At protein level, the expression of OX40L was only slightly modulated by the chemical respiratory sensitizers and irritants, indicating that $\mathrm{OX} 40 \mathrm{~L}$ does not represent a good marker for the prediction of respiratory sensitization (Fig. S5A ${ }^{1}$ ).

The expression of the receptor for TSLP (TSLPr), a cytokine strongly involved in OX40L upregulation on DCs, was increased on THP-1 cells after exposure to chemical sensitizers but not irritants: Exposure to PA and TMA upregulated TSLPr expression on THP-1 cells to $162 \%$ and $151 \%$, respectively, while no relevant differences in its expression were induced by the chemical irritants Acr and $\mathrm{MeSa}$ ( $86 \%$ and $105 \%$ expression, respectively) (Fig. 5A).

TSLPr combines with IL7 receptor $\alpha$ (IL7-R $\alpha$ ) to constitute the high-affinity-binding complex for TSLP, which is able to trigger signaling via the phosphorylation of signal transducer and activator of transcription 5 (P-STAT5), while TSLPr alone has low affinity for its ligand (He and Geha, 2010). IL7-R $\alpha$ expression was upregulated after PA but not TMA exposure and downregulated after Acr but not MeSa exposure (Fig. S5B ${ }^{1}$ ). PA has been classified in the LLNA by topical exposure as a strong sensitizer while TMA was identified as a moderate sensitizer. The different potency of these chemical sensitizers may explain why PA is able to upregulate the expression of IL 7-R $\alpha$ on THP-1 cells while TMA does not.

\subsubsection{Chemokine measurements}

The impact of chemical respiratory sensitizers and chemical respiratory irritants on the cytokine pattern was assessed by measuring cytokine levels in the basolateral compartment using a cytokine multiplex array on a Luminex system.

CCL20 secretion, which triggers DC recruitment to the alveolar barrier, was increased up to 2.5-fold after PA exposure and 2.6-fold after TMA exposure but was not significantly increased in response to the chemical respiratory irritant MeSa (1.6-fold increase) and decreased to 0.1 -fold in response to the irritant Acr (Fig. 5B).

Epithelial-derived GM-CSF is described as an early critical signal in respiratory sensitization (Sheih et al., 2017), which also contributes to the development of asthma (Schuijs et al., 2013). GM-CSF release was upregulated 2.4-fold and 3.4-fold upon exposure to PA and TMA, respectively, compared to their vehicle controls, but decreased to 0.2-fold in response to Acr and was unchanged in response to $\mathrm{MeSa}$ (Fig. 5B).

IL-10, which is secreted by macrophages to prevent DC activation, also allowed the distinction between chemical respiratory sensitizers and chemical respiratory irritants, being induced by sensitizers but not by irritants (Fig. 5B).

On the other hand, IL- $1 \alpha$, which acts on epithelial cells in an autocrine signaling manner to trigger GM-CSF production, RANTES, MCP-1 and IL-7 (Fig. 5B), which are all described as cytokines of interest for the discrimination between respiratory 
A

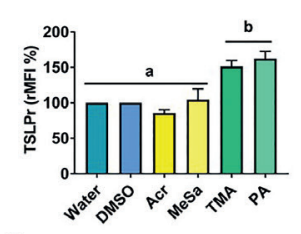

B

\begin{tabular}{|c|c|c|c|c|c|c|}
\hline & CCL20 & GM-CSF & IL-10 & IL-7 & MCP-1 & RANTES \\
\hline Acr & $\mathbf{0 , 1}$ & $\mathbf{0 , 2}$ & $\mathbf{0 , 2}$ & 1,3 & $\mathbf{0 , 1}$ & 1 \\
\hline MeSa & 1,6 & 1 & 1 & 1 & 1,1 & 1,1 \\
\hline TMA & $\mathbf{2 , 6}$ & $\mathbf{3 , 4}$ & 1,5 & 1,3 & 1,1 & 1,5 \\
\hline PA & $\mathbf{2 , 5}$ & $\mathbf{2 , 4}$ & $\mathbf{2}$ & 1,2 & 1,1 & 1,3 \\
\hline
\end{tabular}

C

\begin{tabular}{|c|c|c|c|c|c|c|c|c|}
\hline & CD80 & CIITA & G-CFS-R & HLA-DMA & HLA-DRA & IL1R1-1 & MAP2K1 & MyD88 \\
\hline Acr & $\mathbf{1 , 0}$ & $-0,4$ & $-0,3$ & 0,0 & 0,9 & $-4,3$ & $-0,3$ & $-0,3$ \\
\hline MeSa & 2,4 & 0,6 & 1,1 & 1,0 & 3,6 & $-0,3$ & 0,6 & 0,5 \\
\hline PA & $\mathbf{1 , 2}$ & $-1,8$ & $-0,2$ & $-0,4$ & 0,0 & $\mathbf{1 , 2}$ & 0,1 & $-0,2$ \\
\hline TMA & 0,7 & $-1,3$ & 0,0 & $-0,6$ & $-0,1$ & $\mathbf{1 , 4}$ & 0,1 & $-0,5$ \\
\hline
\end{tabular}

\section{D}

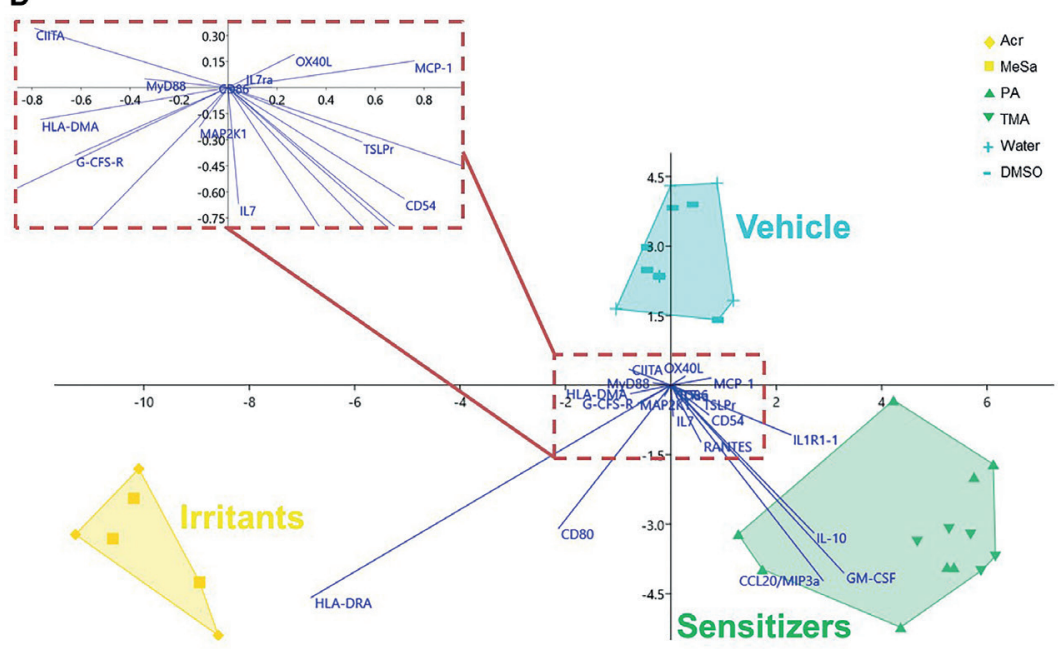

Fig. 5: Differentiation of respiratory sensitizers and irritants based on TSLPr expression and/or GM-CSF, IL-10 and IL1-R1 release in the coculture system (A) TSLPr expression on THP-1 cells in the coculture $24 \mathrm{~h}$ after exposure to chemical sensitizers and irritants at the ALI (mean \pm SEM) $(n=3$, ANOVA + Tukey post hoc test; groups that share the same letters are not significantly different $(p>0.05)$ ). (B) Differential cytokine levels in the coculture $24 \mathrm{~h}$ after exposure to chemical sensitizers and irritants normalized to the vehicle control (Dark blue: induced more than 2-fold; light blue: reduced more than 2-fold). (C) Differential gene expression of relevant markers for sensitization in THP-1 cells $24 \mathrm{~h}$ after exposure to chemical sensitizers and irritants normalized to the vehicle control and expressed on the log2 scale (Dark blue: induced more than 2-fold; light blue: repressed more than 2-fold (or log2 of -1)). (D) Linear discriminant analysis (LDA) indicating which markers (CD86, CD54, IL7ra, TSLPr, and OX40L cell surface markers, CIITA, MyD88, HLA-DMA, HLADRA, CD80, IL1R1-1, and MAP2K1 genes and MCP-1, IL7, IL10, MIP-3a, RANTES, and GM-CSF cytokines) influence the distribution of samples within the different groups (irritants, sensitizers, or controls). Convex hulls gather samples from the same group together and deep blue lines indicates markers influencing the distribution. The red dotted line indicates the part of the LDA that is enlarged. sensitizers and irritants, and other cytokines measured (such as IL-6, sCD40L, IL-25, and IL-33, data not shown) were not differentially modulated by respiratory sensitizers in comparison to respiratory irritants.

\subsubsection{Gene expression measurements}

An assay based on a genomic biomarker signature, the so-called Genomic Allergen Rapid Detection (GARDair), measures hundreds of genes known to be regulated in the MUTZ-3 cell line after exposure to respiratory sensitizers (Forreryd et al., 2015). Based on these findings, a set of genes that are strongly involved in the relevant immune response pathways was measured in THP-1 cells from our coculture.

IL1RL1 (also called ST2), which encodes the IL-33 receptor, allowed discrimination between sensitizers and non-sensitizers with a significantly increased expression following exposure to PA and TMA (Fig. 5C), while expression of CIITA, which encodes major histocompatibility complex class II (MHCII), was decreased after exposure to both PA and TMA (Fig. 5C).
Expression of other genes was not modulated differentially between respiratory sensitizers and irritants.

\subsubsection{Discriminant analysis}

A linear discriminant analysis (LDA) was built in order to investigate which markers most influenced the classification of the compounds as respiratory sensitizers or irritants (Fig. 5D). The LDA allows the distinction between the three groups: vehicle controls, chemical irritants, and chemical respiratory sensitizers. Cell surface markers, cytokines, and gene expression were included in the LDA.

Among all markers tested for the respiratory sensitizers group, GM-CSF, CCL20, IL-10, and IL1R1-1 were the markers that most strongly influenced the distribution of the groups along the axes. RANTES, CD54, and TSLPr allowed discrimination between the three groups only to a lesser extent. Irritant identification was mostly influenced by gene expression of HLA-DRA and CD80, and G-CSF-R and HLA-DMA to a lesser extent. 

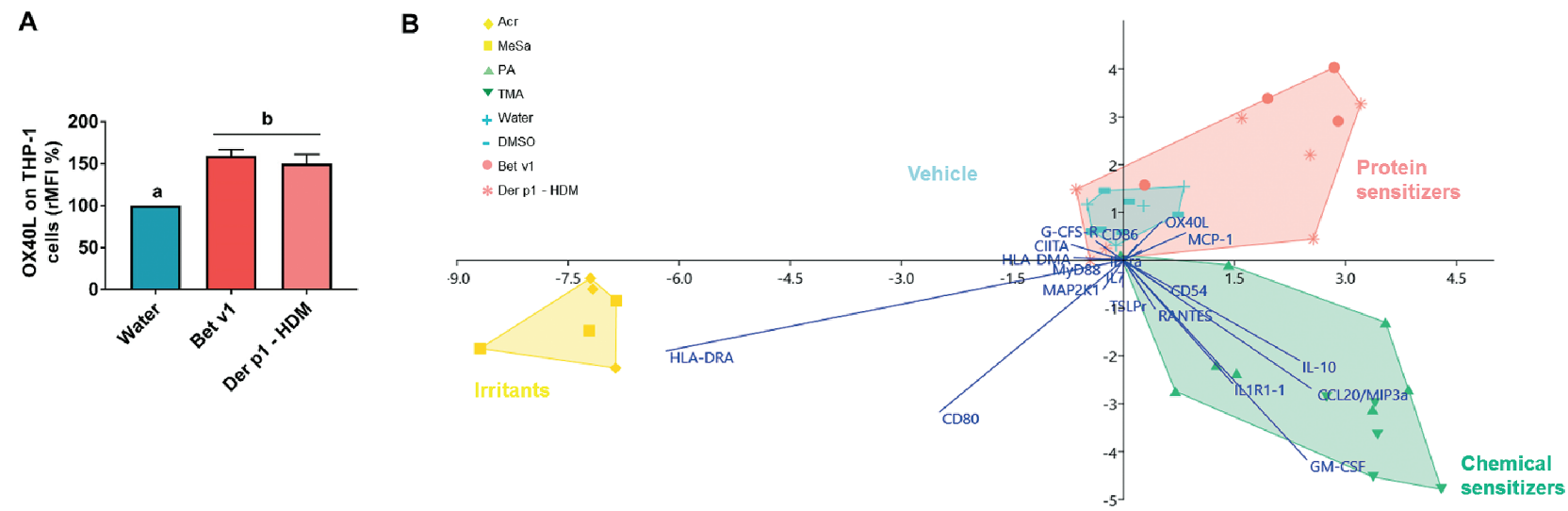

Fig. 6: Differentiation of protein from chemical respiratory sensitizers in the coculture system based on OX40L

(A) OX40L expression on THP-1 cells $24 \mathrm{~h}$ after exposure of the coculture to $0.02 \mu \mathrm{g} / \mathrm{cm}^{2}$ Bet v1 protein and HDM extract containing $0.02 \mu \mathrm{g} / \mathrm{cm}^{2}$ Der p1 (mean \pm SEM, ANOVA + Tukey post hoc test, $\mathrm{n}=3$ ) (Groups that share the same letters are not significantly different $(p>0.05))$. (B) Linear discriminant analysis (LDA) indicating which markers (CD86, CD54, IL7ra, TSLPr, and OX40L cell surface markers, CIITA, MyD88, HLA-DMA, HLA-DRA, CD80, IL1R1-1, and MAP2K1 genes and MCP-1, IL7, IL10, MIP-3a, RANTES, and GM-CSF cytokines) influence the distribution of samples within the different groups (irritants, sensitizers or controls). Convex hulls gather samples from the same group together and deep blue lines indicate markers influencing the distribution.

\subsection{Markers for protein allergens in comparison to chemical sensitizers}

To determine whether the in vitro coculture model proposed here is also able to predict potential respiratory sensitization induced by environmental proteins, the coculture was exposed to different protein allergens such as house dust mite (HDM) extract (corresponding to $0.02 \mu \mathrm{g} / \mathrm{cm}^{2}$ of Der p1) and Bet v1, the major protein allergen from birch pollen $\left(0.02 \mu \mathrm{g} / \mathrm{cm}^{2}\right)$. Both Der $\mathrm{p} 1$ and Bet v1 represent common causes of asthma and seasonal allergy (Gregory and Lloyd, 2011; Weber, 2014).

Exposure to Bet v1 or HDM extract did not influence the viability of the system (Fig. S6A ${ }^{1}$ ). All markers used in our model for the assessment of the respiratory sensitization potential of chemicals were investigated after exposure of the coculture to either protein for $24 \mathrm{~h}$. While exposure to chemical respiratory sensitizers did not influence the OX40L expression on THP-1 cells, exposure to Bet v1 and HDM extract led to the upregulation of OX40L by 1.6 and 1.5-fold, respectively (Fig. 6A).

Although Bet v1 also upregulated other cytokine markers such as IL-10, MCP-1, CCL20, and IL-6, and modulated expression of IL1R1, MAP2K1, G-CSF-R, and CIITA, HDM did not (Fig. $\mathrm{S} 6 \mathrm{~B}, \mathrm{C}^{1}$ ).

LDA performed on protein sensitizers did not allow discriminating them from the vehicle controls (Fig. 6B). The only discriminant markers influencing the distribution of the samples along the axis were the cell surface marker OX40L and the cytokine MCP-1.

\section{Discussion}

One suggested approach to assess the respiratory sensitizing potential of chemicals was to adapt models developed for skin sensitization to respiratory sensitization (Basketter et al., 2017). Tests performed with the DPRA (Direct Peptide Reactivity Assay) present a rich database for chemical respiratory sensitizers while less data is available for the h-CLAT. False negative results are also observed, for instance the respiratory sensitizers PA and hexamethylene diisocyanate (Bloemen et al., 2009) are positive in the in vivo LLNA assay and classified accordingly as strong and extreme sensitizers, but are negative in the h-CLAT (Dearman et al., 2013; Basketter et al., 2017; Ohtake et al., 2018). Although the majority of chemicals that have the potential to induce respiratory sensitization are positive in skin sensitization assays, the assays do not discriminate between skin and respiratory sensitizers. Especially for regulatory needs, the distinction between these two kinds of sensitizers is important as the classification outcome differs, i.e., respiratory sensitizers are considered SVHC while skin sensitizers are not.

In order to overcome these issues, the model presented here was specifically designed to predict respiratory sensitization. Based on current knowledge on the relevant cell interactions involved in respiratory sensitization, we developed and optimized a coculture model of the alveolar barrier that includes alveolar type II epithelial cells, endothelial cells, macrophages, and dendritic cells. Apical exposure to the different compounds through the ALI elicits activation of dendritic like cells. Our hypothesis 
was that the microenvironment not only induces DC activation but also directs the immune response towards a pro-Th2 response through the release of IL- $1 \alpha$ and IL-7 cytokines (Willart et al., 2012; Yeon et al., 2017). The microenvironment could also have an immunosuppressive effect mediated by IL-10 to protect cells from an exaggerated inflammatory response. We hypothesized that the physiological microenvironment directs DC activation in the context of lung sensitization.

To characterize the response of the THP-1 cells in the coculture model in comparison to THP-1 monoculture, we first studied the basal and LPS-induced modulation of the surface markers used as read-out in the h-CLAT. Basal levels of CD54 and CD86 on THP-1 were higher (28-fold and 6-fold, respectively) in the coculture model than in the monoculture. LPS stimulation induced a modest increase in CD86 and CD54 (1.4-fold and 2.4-fold respectively) expression in the coculture, but although CD86 upregulation was similar in the monoculture (1.6-fold), upregulation of CD54 was far greater (20-fold). In the coculture, THP-1 cells are exposed indirectly to the LPS aerosol as the LPS first has to cross the alveolar barrier to activate THP-1 cells, which could explain the lesser upregulation of CD54 as compared to that measured in monoculture where LPS was added to the medium. In addition, even though THP-1 cell density was the same for monoculture and coculture, three additional cell types were present in the coculture, thus reducing the relative number of LPS molecules available for each THP-1 cell in the coculture. Also, the basal expression of CD54 was already 6 times higher in coculture as compared to monoculture, which may explain why the induction of CD54 expression by LPS was not as large in coculture in comparison to monoculture. Finally, the microenvironment produced at the alveolar barrier in the coculture system could also explain the difference in relative cell surface marker expression.

In THP-1 monoculture, both respiratory sensitizers and both irritants that we tested induced an upregulation of CD54 or CD86 that was below the threshold at which a compound is considered a sensitizer in the h-CLAT. These results are different to those of the h-CLAT, which classifies TMA as a sensitizer based on CD86 expression. Similar inconsistencies in the h-CLAT results for the expression of CD86 have been reported before by others (Parise et al., 2015), who obtained CD86 values above the $150 \%$ threshold for only 8 out of 23 chemical skin sensitizers tested.

A first set of compounds comprising two respiratory sensitizers (PA and TMA), two irritants (Acr and MeSa), and two protein sensitizers (HDM and Bet v1) allowed the identification of discriminating markers either on the surface of DCs or released into the basolateral compartment. Thus, the cellular context given by the alveolar barrier seems to play a valuable role in the in vitro detection of chemical respiratory sensitizers. The microenvironment at the epithelial barrier may condition the immune response of DCs (van Rijt and Lambrecht, 2005). Our in vitro coculture model can discriminate between chemical respiratory sensitizers and chemical irritants by measuring expression of CD54 and TSLPr on the surface of DCs $24 \mathrm{~h}$ after exposure. CD54, involved in cellular adhesion, was described in previous studies for the assessment of the skin sensitizing potential of chemicals (Galvão dos Santos et al., 2009). The TSLP cytokine was described in the development of allergic diseases, mostly during sensitization and allergic inflammation to HMW allergens (Reefer et al., 2010) and an increased epithelial expression of TSLP has been shown in patients suffering from asthma (Bosnjak et al., 2011). However, its receptor TSLPr was to the best of our knowledge never measured in the context of the identification of respiratory sensitizers. We found that TSLPr expression on DCs increased in our model 24 $\mathrm{h}$ after exposure to chemical respiratory sensitizers, while no increase was measured after exposure to irritants.

TSLP instructs DCs to mature and drive Th2 polarization by upregulating the expression of co-stimulatory markers such as OX40L. This signaling pathway may explain why, in our model, DCs do not express TSLPr after exposure to either protein sensitizer although the expression of OX40L on DCs is upregulated for both of them. Even though we did not detect an increase of OX40L on the cell surface of THP-1 under the chosen experimental conditions, the OX40L gene expression was demonstrated to be useful for the identification of respiratory chemical sensitizers, helping the discrimination of chemical respiratory sensitizers from both irritants and chemical skin sensitizers (Mizoguchi et al., 2017).

To conclude, we found suitable markers in our optimized model based on a representative set of learning compounds. However, only few substances were tested and additional chemical respiratory sensitizers need to be tested in order to validate the model.

A further improvement would be to also test chemicals that exclusively induce skin sensitization, e.g., dinitrochlorbenzene (DNCB), in order to establish suitable markers that can distinguish respiratory from skin sensitizers.

An additional improvement for the further optimization of our system would be to measure the different endpoints at different time points. For instance, we found no difference between exposed cells and the vehicle control for CD86 and CD80 mRNA expression in THP-1 cells after $24 \mathrm{~h}$. However, Mizoguchi et al. (2017) found increased expression of these genes $9 \mathrm{~h}$ after exposure to these chemicals in monocytes in a submerged coculture system using the bronchiolar BEAS-2B cell line. Similarly, adding earlier measuring timepoints to the in chemico method DPRA, validated in 2015 by OECD to assess the sensitizing potential of chemicals (Lalko et al., 2012; OECD, 2015), resulted in a better accuracy and allowed determination of the potency of the sensitizers (Wareing et al., 2017).

Based on the data from this proof-of-concept study using one representative concentration per chemical (yielding comparable cytotoxicity where possible), a further important step could be the measurement of concentration-dependent responses in order to better discriminate the responses to different chemicals and to obtain information relevant for potency assessment. In our model, the concentration CV75 was used as a starting point based on experience from the h-CLAT. While the CV75 could be useful for the determination of cell surface marker expression, the use of subtoxic concentrations may be more appropriate for the gene expression and cytokine measurements. For instance, when subtoxic concentrations of respiratory sensitizers and irritants were tested in an in vitro lung capillary barrier comprising bronchiolar club cells NCIH-441 and microvascular endothelial cells ISO- 
HAS-1 in submerged conditions, Hermann et al. (2015) identified RANTES as a cytokine able to discriminate respiratory sensitizers from irritants, while in our model TMA but not PA induced an increase of RANTES release. Instead, upregulation of the release of GM-CSF, MIP-3 $\alpha /$ CCL20, and IL-10 appeared to discriminate between chemical sensitizers and irritants in our system. Therefore, testing different concentrations of chemicals could indicate whether CV75 is optimal in our model, considering that some chemicals are nontoxic and therefore cannot be tested at CV75.

The difference between the levels of cellular viability at which the two irritants were tested in this study could also explain why we observed such great differences in cytokine expression. MIP$3 \alpha /$ CCL2 0 and MCP-1 released into the basolateral compartment were strongly down-regulated after exposure to Acr while no difference was observed after MeSa exposure. Similarly, MeSa exposure induced upregulation of G-CSF, HLA-DMA, and HLADRA genes while Acr did not. Forreryd et al (2015) used CV90 for the GARD assay for respiratory sensitizers to establish the genomic signature of the MUTZ-3 dendritic like cell line.

Particular attention needs also to be given to the solubility of the compounds. Certain sensitizers are water insoluble, e.g., diisocyanates, or are hydrolyzed in water, e.g., acid anhydrides, which may be the reason for false negative results in the h-CLAT. The low solubility of some compounds also represents a limiting factor in our model. The use of compounds such as hexamethylene diisocyanate remains problematic as it polymerizes in contact with water, making nebulization impossible. Extensive work needs to be done in order to be able to expose our system to all kinds of chemical compounds at the ALI.

HMW allergens such as pollen grains were initially believed to be unable to reach the lower airways and thus to induce an immune response there. However, a small percentage of largesized particles may penetrate into the lower airways (Michel et al., 1977). The lower airways, and in particular alveoli, are of interest for respiratory sensitization as DC provide robust air surveillance at this site (Thornton et al., 2012). The presence of alveolar type II epithelial cells, as we have in our model, is important for HMW sensitization assessment as it has been demonstrated that lung surfactant proteins SP-A and SP-D from alveolar type II cells attenuate allergic inflammation by directly binding to the protein allergens (Stewart et al., 2014). Therefore, the use of our model is justified also for the testing of HMW allergens. Most of the markers identified for chemical respiratory sensitizers were not upregulated upon exposure to HMW sensitizers. Indeed, only OX40L expression on THP-1 cells was up-regulated after exposure to HMW sensitizers, while this marker was down-regulated after exposure to either irritant. OX40L thus could be used for the identification of HMW respiratory sensitizers in our model.

The mechanism of action of HMW sensitizers differs from that of chemical respiratory sensitizers. Many known HMW allergens, such HDM or pollen, have a protease activity, which can disrupt the barrier function of the epithelial layer by cleaving tight junctions, facilitating the passage of allergen across the epithelial surface and hence activating protease-dependent and protease-independent signaling pathways (Kauffman et al., 2006; Hammad et al., 2009). It is still unclear how important the protease activity is as this is not a general feature of all protein allergens (Papazian et al., 2015). In our model, the release of MCP-1, IL-10, MIP-3 $\alpha$ / CCL20, and IL-6 was increased in the basolateral compartment compared to the vehicle control after exposure to Bet v1 but not to HDM. This may be due to the different forms of the allergen. Kauffman et al. (2006) observed different dose response curves of IL-6 release by A549 cells in response to natural purified Der p1 versus whole HDM extract and found lower IL-6 and IL-8 release at the highest concentrations used (Kauffman et al., 2000, 2006). Using lower concentrations of HDM in our model may have resulted in differences in cytokines release.

Sensitization and subsequent allergic reaction could occur after repeated exposure to compounds. However, it is not possible to do multiple exposures in our model at this time. Extensive work has to be done in order to investigate for how long it can be cultured.

We focused our research on the alveolar part of the lung, but the system could be adapted to represent other parts of the respiratory tract such as the nose, the trachea and the bronchi to assess the respiratory sensitizing potential of chemicals through the complete respiratory system.

In conclusion, the learning set of compounds showed that TSLPr and CD54 cell surface marker expression, IL-10, GM-CSF, and CCL20 cytokine release, and IL1-R1 gene expression $24 \mathrm{~h}$ after exposure may be used to differentiate chemical respiratory sensitizers from irritants in our model, and OX40L cell surface marker expression could be used to identify HMW respiratory sensitizers.

\section{References}

Akdis, M., Burgler, S., Crameri, R. et al. (2011). Interleukins, from 1 to 37, and interferon- $\gamma$ : Receptors, functions, and roles in diseases. J Allergy Clin Immunol 127, 701-721.e70. doi:10.1016/j.jaci.2010.11.050

Anderson, S. E., Siegel, P. D. and Meade, B. J. (2011). The LLNA: A brief review of recent advances and limitations. $J$ Allergy (Cairo) 2011, 424203. doi:10.1155/2011/424203

Ashikaga, T., Yoshida, Y., Hirota, M. et al. (2006). Development of an in vitro skin sensitization test using human cell lines: The human cell line activation test (h-CLAT). I. Optimization of the h-CLAT protocol. Toxicol In Vitro 20, 767-773. doi:10.1016/j.tiv.2005.10.012

Basketter, D., Poole, A. and Kimber, I. (2017). Behaviour of chemical respiratory allergens in novel predictive methods for skin sensitisation. Regul Toxicol Pharmacol 86, 101-106. doi:10.1016/j.yrtph.2017.03.002

Bedoret, D., Wallemacq, H., Marichal, T. et al. (2009). Lung interstitial macrophages alter dendritic cell functions to prevent airway allergy in mice. J Clin Invest 119, 3723-3738. doi:10.1172/JCI39717

Bloemen, K., Verstraelen, S., Schoeters, G. et al. (2009). The Collection and Evaluation of Data on Incidence and Severity of Skin and Respiratory Allergy Related to Exposure of Chemicals from Non-Food Sources. Annex VI Chemical Reports, Respiratory sensitizers. Mol, Belgium: VITO NV. https:// 
ec.europa.eu/health/sites/health/files/scientific_committees/ docs/vito_study_allergy_en.pdf

Bosnjak, B., Stelzmueller, B., Erb, K. J. and Epstein, M. M. (2011). Treatment of allergic asthma: Modulation of Th2 cells and their responses. Respir Res 12, 114. doi:10.1186/14659921-12-114

Butterfield, J. H., Weiler, D., Dewald, G. and Gleich, G. J. (1988). Establishment of an immature mast cell line from a patient with mast cell leukemia. Leuk Res 12, 345-355. doi:10. 1016/0145-2126(88)90050-1

Chung, K. F. and Adcock, I. M. (2014). Biology of monocytes and macrophages. In N. F. Adkinson, B. S. Bochner, A. W. Burks et al. (eds.), Middleton's Allergy: Principles and Practice (292-301). $8^{\text {th }}$ edition. London, UK: Elsevier.

Clouet, E., Kerdine-Römer, S. and Ferret, P.-J. (2017). Comparison and validation of an in vitro skin sensitization strategy using a data set of 33 chemical references. Toxicol In Vitro 45, 374-385. doi:10.1016/j.tiv.2017.05.014

Daigneault, M., Preston, J. A., Marriott, H. M. et al. (2010). The identification of markers of macrophage differentiation in PMA-stimulated THP-1 cells and monocyte-derived macrophages. PLoS One 5, e8668. doi:10.1371/journal.pone. 0008668

Dearman, R. J., Basketter, D. A. and Kimber, I. (2013). Inter-relationships between different classes of chemical allergens. $J$ Appl Toxicol 33, 558-565. doi:10.1002/jat.1758

Dik, S., Pennings, J. L. A., van Loveren, H. and Ezendam, J. (2015). Development of an in vitro test to identify respiratory sensitizers in bronchial epithelial cells using gene expression profiling. Toxicol In Vitro 30, 274-280. doi:10.1016/j. tiv.2015.10.010

EC - European Commission (2006). Regulation (EC) No 1907/ 2006. https://eur-lex.europa.eu/legal-content/EN/TXT/?uri= CELEX\%3A02006R1907-20140410

EURL ECVAM (2015). EURL ECVAM Recommendation on the human Cell Line Activation Test (h-CLAT) for Skin Sensitisation Testing. https://bit.ly/2TVWHKX

Fizeșan, I., Chary, A., Cambier, S. et al. (2018). Responsiveness assessment of a 3D tetra-culture alveolar model exposed to diesel exhaust particulate matter. Toxicol In Vitro 53, 67-79. doi:10.1016/j.tiv.2018.07.019

Forreryd, A., Johansson, H., Albrekt, A.-S. et al. (2015). Prediction of chemical respiratory sensitizers using GARD, a novel in vitro assay based on a genomic biomarker signature. PLoS One 10, e0118808. doi:10.1371/journal.pone.0118808

Galvão dos Santos, G., Reinders, J., Ouwehand, K. et al. (2009). Progress on the development of human in vitro dendritic cell based assays for assessment of the sensitizing potential of a compound. Toxicol Appl Pharmacol 236, 372-382. doi:10.1016/j.taap.2009.02.004

Gregory, L. G. and Lloyd, C. M. (2011). Orchestrating house dust mite-associated allergy in the lung. Trends Immunol 32, 402-411. doi:10.1016/j.it.2011.06.006

Hammad, H., Chieppa, M., Perros, F. et al. (2009). House dust mite allergen induces asthma via Toll-like receptor 4 triggering of airway structural cells. Nat Med 15, 410-416. doi:10.1038/ nm. 1946

Hammad, H. and Lambrecht, B. N. (2011). Dendritic cells and airway epithelial cells at the interface between innate and adaptive immune responses. Allergy 66, 579-587. doi:10.1111/ j.1398-9995.2010.02528.x

He, R. and Geha, R. S. (2010). Thymic stromal lymphopoietin. Ann N Y Acad Sci 1183, 13-24. doi:10.1111/j.1749-6632. 2009.05128.x

Hermanns, M. I., Kasper, J. Y., Unger, R. E. et al. (2015). Assessment of respiratory sensitizers: Cytokine responses in a $3 \mathrm{D}$ alveolo-capillary barrier model in vitro. Advanced Biomaterials and Devices in Medicine 2, 1-9.

Holt, P. G. (2012). Pulmonary dendritic cells in local immunity to inert and pathogenic antigens in the respiratory tract. Proc Am Thorac Soc 2, 116-120. doi:10.1513/pats.200502-017AW

Huang, S., Wiszniewski, L., Constant, S. and Roggen, E. (2013). Potential of in vitro reconstituted 3D human airway epithelia (MucilAir $^{\mathrm{TM}}$ ) to assess respiratory sensitizers. Toxicol In Vitro 27, 1151-1156. doi:10.1016/j.tiv.2012.10.010

Kauffman, H. F., Tomee, J. F., van de Riet, M. A. et al. (2000). Protease-dependent activation of epithelial cells by fungal allergens leads to morphologic changes and cytokine production. J Allergy Clin Immunol 105, 1185-1193. doi:10.1067/ mai.2000.106210

Kauffman, H. F., Tamm, M., Timmerman, J. A. and Borger, P. et al. (2006). House dust mite major allergens Der $p 1$ and Der $p 5$ activate human airway-derived epithelial cells by protease-dependent and protease-independent mechanisms. Clin Mol Allergy 4, 5. doi:10.1186/1476-7961-4-5

Kimber, I., Basketter, D. A. and Dearman, R. J. (2010). Chemical allergens - What are the issues? Toxicology 268, 139-142. doi:10.1016/j.tox.2009.07.015

Kimber, I., Dearman, R. J., Basketter, D. A. and Boverhof, D. R. (2014). Chemical respiratory allergy: Reverse engineering an adverse outcome pathway. Toxicology 318, 32-39. doi:10.1016/j.tox.2014.02.001

Klein, S. G., Serchi, T., Hoffmann, L. et al. (2013). An improved $3 \mathrm{D}$ tetraculture system mimicking the cellular organisation at the alveolar barrier to study the potential toxic effects of particles on the lung. Part Fibre Toxicol 10, 31. doi:10. 1186/1743-8977-10-31

Klein, S. G., Cambier, S., Hennen, J. et al. (2017). Endothelial responses of the alveolar barrier in vitro in a dose-controlled exposure to diesel exhaust particulate matter. Part Fibre Toxicol 14, 7. doi:10.1186/s12989-017-0186-4

Kumari, A., Dash, D. and Singh, R. (2015). Lipopolysaccharide (LPS) exposure differently affects allergic asthma exacerbations and its amelioration by intranasal curcumin in mice. Cytokine 76, 334-342. doi:10.1016/j.cyto.2015.07.022

Lacroix, G., Koch, W., Ritter, D. et al. (2018). Air-liquid interface in vitro models for respiratory toxicology research: Consensus workshop and recommendations. Appl In Vitro Toxicol 4,91-106. doi:10.1089/aivt.2017.0034

Lalko, J. F., Kimber, I., Gerberick, G. F. et al. (2012). The direct peptide reactivity assay: Selectivity of chemical respiratory allergens. Toxicol Sci 129, 421-431. doi:10.1093/toxsci/kfs205 
Lambrecht, B. N. and Hammad, H. (2003). Taking our breath away: Dendritic cells in the pathogenesis of asthma. Nat Rev Immunol 3, 994-1003. doi:10.1038/nri1249

Lambrecht, B. N. and Hammad, H. (2015). The immunology of asthma. Nat Immunol 16, 45-56. doi:10.1038/ni.3049

Lauzon-Joset, J.-F., Marsolais, D., Langlois, A. and Bissonnette, E. Y. (2014). Dysregulation of alveolar macrophages unleashes dendritic cell-mediated mechanisms of allergic airway inflammation. Mucosal Immunol 7, 155-164. doi:10.1038/mi. 2013.34

Lenz, A. G., Karg, E., Lentner, B. et al. (2009). A dose-controlled system for air-liquid interface cell exposure and application to zinc oxide nanoparticles. Part Fibre Toxicol 6, 32. doi:10.1186/1743-8977-6-32

Lieber, M., Todaro, G., Smith, B. et al. (1976). A continuous tumor-cell line from a human lung carcinoma with properties of type II alveolar epithelial cells. Int J Cancer 17, 62-70. doi:10.1002/ijc.2910170110

Liu, A. H. (2002). Endotoxin exposure in allergy and asthma: Reconciling a paradox. J Allergy Clin Immunol 109, 379-392. doi:10.1067/mai.2002.122157

Marescotti, D., Serchi, T., Luettich, K. et al. (2019). How complex should an in vitro model be? Evaluation of complex 3D alveolar model with transcriptomic data and computational biological network models. ALTEX 36, 388-402. doi:10.14573/ altex.1811221

Michel, F. B., Marty, J. P., Quet, L. and Cour, P. (1977). Penetration of inhaled pollen into the respiratory tract. Am Rev Respir Dis 115, 609-616. doi:10.1164/arrd.1977.115.4.609

Miyazawa, M., Ito, Y., Yoshida, Y. et al. (2007). Phenotypic alterations and cytokine production in THP-1 cells in response to allergens. Toxicol In Vitro 21, 428-437. doi:10.1016/j. tiv.2006.10.005

Mizoguchi, I., Ohashi, M., Chiba, Y. et al. (2017). Prediction of chemical respiratory and contact sensitizers by ox401 expression in dendritic cells using a novel 3D coculture system. Front Immunol 8, 929. doi:10.3389/fimmu.2017.00929

OECD - Organisation for Economic Co-operation and Development (2015). Test No. 442C: In Chemico Skin Sensitisation: Direct Peptide Reactivity Assay (DPRA). OECD Guidelines for the Testing of Chemicals, Section 4. OECD Publishing, Paris. doi:10.1787/9789264229709-en

OECD (2018). Test No. 442E: In Vitro Skin Sensitisation - In Vitro Skin Sensitisation: In Vitro Skin Sensitisation assays addressing the Key Event on activation of dendritic cells on the Adverse Outcome Pathway for Skin Sensitisation. OECD Guidelines for the Testing of Chemicals, Section 4. OECD Publishing, Paris. doi:10.1787/9789264264359-en.

Ohtake, T., Maeda, Y., Hayashi, T. et al. (2018). Applicability of an integrated testing strategy consisting of in silico, in chemico and in vitro assays for evaluating the skin sensitization potencies of isocyanates. Toxicology 393, 9-14. doi:10.1016/j. tox.2017.10.015

Otsubo, Y., Nishijo, T., Miyazawa, M. et al. (2017). Binary test battery with KeratinoSens ${ }^{\mathrm{TM}}$ and h-CLAT as part of a bottom-up approach for skin sensitization hazard predic- tion. Regul Toxicol Pharmacol 88, 118-124. doi:10.1016/j. yrtph.2017.06.002

Papazian, D., Wagtmann, V. R., Hansen, S. and Würtzen, P. A. (2015). Direct contact between dendritic cells and bronchial epithelial cells inhibits $\mathrm{T}$ cell recall responses towards mite and pollen allergen extracts in vitro. Clin Exp Immunol 181, 207-218. doi:10.1111/cei.12611

Parise, C. B., Sá-Rocha, V. M. and Moraes, J. Z. (2015). Skin sensitizer identification by IL-8 secretion and CD86 expression on THP-1 cells. Toxicol In Vitro 30, 318-324. doi:10.1016/j. tiv.2015.10.004

Pridgeon, C. S., Schlott, C., Wong, M. W. et al. (2018). Innovative organotypic in vitro models for safety assessment: Aligning with regulatory requirements and understanding models of the heart, skin, and liver as paradigms. Arch Toxicol 92, 557569. doi:10.1007/s00204-018-2152-9

Reefer, A. J., Hulse, K. E., Lannigan, J. A. et al. (2010). Flow cytometry imaging identifies rare Th2 cells expressing tslp receptor in a "proallergic" milieu. J Allergy Clin Immunol 126, 1049-105910. doi:10.1016/j.jaci.2010.07.023

Sakaguchi, H., Ashikaga, T., Miyazawa, M. et al. (2009). The relationship between CD86/CD54 expression and THP-1 cell viability in an in vitro skin sensitization test--human cell line activation test (h-CLAT). Cell Biol Toxicol 25, 109-126. doi:10.1007/s10565-008-9059-9

Schuijs, M. J., Willart, M. A., Hammad, H. and Lambrecht, B. N. (2013). Cytokine targets in airway inflammation. Curr Opin Pharmacol 13, 351-361. doi:10.1016/j.coph.2013.03.013

Sheih, A., Parks, W. C. and Ziegler, S. F. (2017). GM-CSF produced by the airway epithelium is required for sensitization to cockroach allergen. Mucosal Immunol 10, 705-715. doi:10.1038/mi.2016.90

Sibille, Y. and Reynolds, H. Y. (1990). Macrophages and polymorphonuclear neutrophils in lung defense and injury. Am Rev Respir Dis 141, 471-501. doi:10.1164/ajrccm/141.2.471

Stewart, G. A., Richardson, J. P., Zhang, J. et al. (2014). The structure and function of allergens. In N. F. Adkinson, B. S. Bochner, A. W. Burks et al. (eds.), Middleton's Allergy (398429). London, UK: Elsevier.

Strickland, J., Zang, Q., Paris, M. et al. (2017). Multivariate models for prediction of human skin sensitization hazard. $J$ Appl Toxicol 37, 347-360. doi:10.1002/jat.3366

Sullivan, K. M., Enoch, S. J., Ezendam, J. et al. (2017). An adverse outcome pathway for sensitization of the respiratory tract by low-molecular-weight chemicals: Building evidence to support the utility of in vitro and in silico methods in a regulatory context. Appl In Vitro Toxicol 3, 213-226. doi:10.1089/ aivt.2017.0010

Thornton, E. E., Looney, M. R., Bose, O. et al. (2012). Spatiotemporally separated antigen uptake by alveolar dendritic cells and airway presentation to T cells in the lung. J Exp Med 209, 1183-1199. doi:10.1084/jem.20112667

Torén, K. and Blanc, P. D. (2009). Asthma caused by occupational exposures is common - A systematic analysis of estimates of the population-attributable fraction. BMC Pulm Med 9, 7. doi:10.1186/1471-2466-9-7 
Toussaint, M., Fievez, L., Drion, P.-V. et al. (2013). Myeloid hypoxia-inducible factor $1 \alpha$ prevents airway allergy in mice through macrophage-mediated immunoregulation. Mucosal Immunol 6, 485-497. doi:10.1038/mi.2012.88

Tsuchiya, S., Yamabe, M., Yamaguchi, Y. et al. (1980). Establishment and characterization of a human acute monocytic leukemia cell line (THP-1). Int J Cancer 26, 171-176. doi:10.1002/ ijc. 2910260208

Wareing, B., Urbisch, D., Kolle, S. N. et al. (2017). Prediction of skin sensitization potency sub-categories using peptide reactivity data. Toxicol In Vitro 45, 134-145. doi:10.1016/j. tiv.2017.08.015

Weber, R. W. (2014). Aerobiology of outdoor allergens. In N. F. Adkinson, B. S. Bochner, A. W. Burks et al. (eds.), Middleton's Allergy: Principles and Practice (430-452). $8^{\text {th }}$ edition. London, UK: Elsevier.

Willart, M. A. M., Deswarte, K., Pouliot, P. et al. (2012). Interleukin-1 $\alpha$ controls allergic sensitization to inhaled house dust mite via the epithelial release of GM-CSF and IL-33. J Exp Med 209, 1505-1517. doi:10.1084/jem.20112691

van Helden, M. J. and Lambrecht, B. N. (2013). Dendritic cells in asthma. Curr Opin Immunol 25, 745-754. doi:10.1016/j. coi.2013.10.002

van Rijt, L. S. and Lambrecht, B. N. (2005). Dendritic cells in asthma: A function beyond sensitization. Clin Exp Allergy 35, 1125-1134. doi:10.1111/j.1365-2222.2005.02321.x

Yeon, S., Halim, L., Chandele, A. et al. (2017). IL-7 plays a critical role for the homeostasis of allergen-specific memory CD4 T cells in the lung and airways. Sci Rep 7, 11155. doi:10.1038/ s41598-017-11492-7

\section{Conflict of interest}

The authors declare they have no conflicts of interest.

\section{Authors' contributions}

AC planned and performed the experiments at the ALI, performed the data evaluation and produced all figures and tables. EM contributed to the experiments on cellular viability. $\mathrm{BB}, \mathrm{JH}$, and $\mathrm{AC}$ were involved in the design of the flow cytometry experiments. JE performed cytokines measurements. SC and AC designed and performed the qRT-PCR experiments and were responsible for the evaluation of gene expression. TS and ACG supervised planning of experiments, daily work and general experimental planning. All authors contributed significantly to the interpretation of data and the preparation of the manuscript. All authors approved the final manuscript.

\section{Acknowledgment}

The contribution of AC, TS, ACG and SC was made possible by the LIST financed internal project Chemsens (2013-2017), the contribution of AC, TS and ACG was made possible by the VitralizeMe project (PoC18/12559604; 2018-2020) funded by the National Research Fund Luxembourg and the contribution of EM, TS, ACG was made possible by the LIST financed internal project IMPERIS (2017-2018). We thank the Luxembourg Centre for Systems Biomedicine (LCSB) for help and support with the flow cytometry analysis. The authors thank Servane Contal for her great assistance during the practical work of this study. 